\title{
9 \\ BEYOND LAND \\ Indigenous health and self-determination in an age of urbanisation
}

\author{
Maria John
}

This chapter examines how Indigenous peoples in the United States and Australia worked out the potential for their self-determination beyond claims to land or territory - that is, in the pursuit of self-governance over two interconnected realms: health services and individual bodily health. In doing so, the chapter seeks to make a case for the significant role played by urban Indigenous health struggles in reframing and reshaping the broader project of Indigenous self-determination in the twentieth and twenty-first centuries.

In the context of past and continuing colonisation, the political projects of sovereignty and self-determination have long been touchstones for Indigenous communities. One might assume, however, that these terms have come to hold special (and potentially new) significance over the last 30 years or so. Within Indigenous political discourse, the language of sovereignty was invoked almost exclusively in relation to legal and territorial claims until around the 1990s, but even a cursory glance at recent protest placards from Indigenous political rallies across the globe, or at new monograph titles containing the word 'sovereignty' within Indigenous studies, reveals a vastly broadened discourse around this term. Diverse conceptual sovereignties including cultural, intellectual, visual and sexual, to name a few, have now become prevalent within Indigenous studies. For instance, in her important work theorising 'visual sovereignty', Michelle Raheja (Seneca) defines this as a 'creative act of self-representation that 
has the potential to both undermine stereotypes of Indigenous peoples and to strengthen ... the intellectual "health" of communities in the wake of genocide and colonialism'. ${ }^{1}$ In one of the fastest growing research areas within Indigenous studies, scholars and communities are defining 'food sovereignty' as 'the right of peoples to healthy and culturally appropriate food produced through ecologically sound and sustainable methods, and their right to define their own food and agriculture systems. ${ }^{2}$

In part, I think these changes reveal that, in recent decades, there has been some blending of the terms 'sovereignty' and 'self-determination'. They are often used interchangeably. More than this, however, we are also seeing that what increasingly is meant by 'sovereignty' is self-determination because self-determination can refer to matters of ownership, control and access. Within Indigenous politics, self-determination is commonly understood as a right Indigenous communities and individuals have to determine their economic, social and cultural development. Illustrating the ways in which self-determination has become central to Indigenous peoples' ideas about, and practices of, sovereignty, we might note that a seminal 2005 monograph edited by Indigenous Studies scholar Joanne Barker (Lenape) blends the terms sovereignty and self-determination even within the book's title: Sovereignty Matters: Locations of Contestation and Possibility in Indigenous Struggles for Self-Determination. ${ }^{3}$ In her Introduction Barker explains:

Following World War II, sovereignty emerged not as a new but as a particularly valued term within indigenous political discourses to signify a multiplicity of legal and social rights to political, economic, and cultural self-determination ... It has come to mark the complexities of global indigenous efforts to reverse ongoing experiences of colonialism as well as to signify local efforts at the reclamation of specific territories, resources, governments, and cultural knowledge and practices. ${ }^{4}$

While Barker is also rightly at pains to emphasise that not all Indigenous peoples share 'the same understanding of what sovereignty is or how it matters', her discernment that sovereignty has come to encompass both legal and social rights to self-determination in multiple realms

1 Raheja, 'Reading Nanook's', 1161.

2 Nyéléni, 'Declaration of Nyéléni', Forum for Food Sovereignty, 27 February 2007, accessed

15 August 2020, nyeleni.org/spip.php?article290.

3 Barker, Sovereignty.

4 Barker, Sovereignty, 1. 
(economic, cultural, etc.) and, crucially, to refer to the conjoined projects of reversing (ongoing experiences of colonialism) and reclaiming (specific resources, lands, practices, etc.), underscores not only the very broad contexts in which sovereignty is now a meaningful concept and project for Indigenous peoples, but also the very central role that a principle of self-determination plays within this expanded pursuit of sovereignty.

And while it would be another two years before the United Nations Declaration on the Rights of Indigenous Peoples (UNDRIP) was signed in 2007, given the centrality of the language of 'self-determination' within that document, it is important to clarify here that the model of selfdetermination established by the declaration sits at odds with the much broader visions of sovereignty and self-determination to which I refer in this chapter, and which are discussed by Barker (and by others). As many critics of the declaration point out, a close reading of the rights protected by the UNDRIP shows that they are both less powerful than they appear and that they are limited and superseded by the human rights framework in which they are embedded. Legal scholar Karen Engle expresses this last problem succinctly when noting that the Indigenous right to selfdetermination recognised by the UNDRIP takes the form of 'a collective human rights demand rather than a claim for statehood'. ${ }^{5}$ While the document has been lauded by many for its recognition of collective rights, the right to culture, and self-determination for Indigenous peoples, it is also heavily critiqued for not doing enough. Most problematically, it was clear the UN system actively sought to adopt a stance of ambiguity towards the meaning of self-determination as specifically applied to Indigenous peoples. The result has been that the declaration is clear in limiting its recognition of Indigenous self-determination to 'internal' matters only, stating: the right to self-determination guarantees only 'the right to autonomy or self-government in matters relating to their internal and local affairs' . 'This language makes it clear that strong forms of Indigenous self-determination, which might threaten the sovereignty and territorial integrity of nationstates, would not be recognised or protected by the United Nations.

In contrast, the melding of the political language and goals of sovereignty and self-determination, which I seek to address in this chapter, includes within the wider purview of an 'expanded' sovereignty, the goals of reversing and reclaiming as described above. While the sovereignty and 
self-determination of which Barker speaks are not exclusively or even primarily about these two goals (goals that certainly might be seen to more explicitly challenge the sovereignty of nation-states), the fact that reversing and reclaiming are a part of Indigenous peoples' projects of sovereignty and self-determination means we must understand this in a different light to the kind of self-determination expressed within the UNDRIP. One might even speculate that the recent rise in the use of the language of 'sovereignty' has been a strategy to escape the limitations of the UNDRIP. Within this chapter, I distill the strengthening conceptual tie between sovereignty and self-determination into the idea that both concepts have become increasingly interchangeable, since both are increasingly used, most crucially, to refer to the ability to be self-governing (understood broadly). This is the core of the many different ways in which Indigenous political actors and theorists are invoking sovereignty in new ways and in new contexts.

The shift towards something more closely resembling self-determination when speaking of sovereignty, and the frequent interchange we now see between these terms, should also be understood against another key development. That is, a critique that argues for the necessity of rewriting or 'decolonising' the concept of sovereignty within Indigenous political discourse. As the critique goes, the concept of sovereignty (and the modern nation-state) is rooted in European monarchies, hierarchical power structures and traditions of jurisprudence. As such, because these kinds of governing structures were typically foreign to Indigenous peoples, sovereignty is said to be ill-suited to their political conceptions of community. Mohawk activist and scholar Taiaiake Alfred is an oft-cited proponent of this critique, calling for the rejection of state sovereigntist discourse in Indigenous politics because of its connection to European colonialism:

The next phase of scholarship and activism, then, will need to transcend the mentality that supports the colonisation of Indigenous nations, beginning with the rejection of the term and notion of Indigenous sovereignty. ${ }^{7}$

In this sense, one might again speculate that the recent rise in the use of the language of self-determination when discussing 'sovereignty' has also been a strategy to escape the colonial implications of traditional 'sovereigntist' discourse.

7 Alfred, 'Sovereignty', 39-40. 
Although such critiques might help us understand the supplanting, or at least the converging of sovereignty talk with the language and goals of self-determination, this shift has not been universally accepted. Influential scholar and activist Vine Deloria Jr (Standing Rock Sioux), for instance, memorably critiqued the growing ubiquity of the concept of sovereignty within Indigenous politics and its straying from non-legal matters: 'Today the definition of sovereignty covers a multitude of sins, having lost its political moorings, and now is adrift on the currents of individual fancy'. ${ }^{8}$

My interest in this convergence and expansion of the ways in which Indigenous peoples, scholars and communities are engaging with concepts of sovereignty and self-determination is, in the first instance, less about what has been gained or lost in this endeavour. As a historian, I seek to bring to light the lived experiences and historical contexts out of which this discursive and political reconfiguring has emerged. In particular, my attention is drawn to a neglected context in which the language of selfdetermination has always been central to Indigenous political struggles: health. Health and medical contexts also emerge as a logical place to look for the political configurations around contemporary Indigenous claims to self-determination and sovereignty once we recognise the potent ways in which health statistics have steadily become one of the starkest means of illustrating levels of historical and continuing injustice experienced by Indigenous peoples in places like the United States, Canada and Australia. This chapter considers recent rearticulations of Indigenous self-determination and sovereignty within health contexts by Indigenous communities in settler states. In particular, I ask what the example of urban Indigenous community-controlled health services in the United States and Australia can tell us about a new and distinctly urban, non-territorial form of Indigenous self-determination that emerged in these nations during the 1970s. What happens to our understanding of self-determination if we attempt to decentre, or if we look beyond, land claims?

I compare the establishment of the Seattle Indian Health Board (Seattle) and the Aboriginal Medical Service (AMS) (Sydney) in this chapter, as these clinics were among the first Indigenous community-controlled health services in their respective national contexts, and formed in response to similar struggles. Although they did embrace a diasporic and 
multiethnic vision of the future (marking a distinct departure from forms of Indigenous political community that formed the basis of sovereignty claims in the past), I argue that the ideals of self-determination these clinics represented were not inconsistent with forms of sovereignty pursued by Indigenous communities tied to traditional homelands. By considering the political discourse and the events from which these clinics emerged, we see that the activists who created these health services, and who advocated for a model of self-determination distinct from land claims, stood in solidarity with rural and urban traditional landowners, even as they argued for the urgency of reimagining the project of Indigenous selfdetermination as governance over social services. The history and legacy of these two health organisations becomes, I argue, a vivid example of how Indigenous people reconfigured the terrain upon which their claims to sovereignty and self-determination (understood as self-governance) could be pursued.

In the remaining sections of this chapter, I will first trace the origins of the Seattle Indian Health Board and the AMS. Though having little direct connection to each other at the time of their founding, I suggest these clinics might nonetheless be understood within the same historical frame given the political struggles and health crises that led to their development. Finally, by making a case for the importance of recognising the simultaneous emergence of these separate clinics as markers of a shared historical and political experience, this chapter uses their histories to foreground a view of Indigenous self-determination as a non-territorial project, and a transnational Indigenous response to government policies of urbanisation and assimilation pursued across settler states.

\section{A catalyst for change: Indigenous urbanisation and a crisis of health care access}

Beginning in 1970, in major US and Australian cities, urban Indigenous communities in places like Seattle, Minneapolis, Sydney and Melbourne, started establishing their own grassroots, community-controlled health services. These clinics aimed to provide free medical care by Native people, for Native people. To this day, Indigenous community-controlled health services are still operational. Health experts agree this model of healthcare 
delivery has been transformative for the Indigenous communities they serve. ${ }^{9}$ Indeed, evidencing this, Indigenous community-controlled health services have grown steadily since the 1970 s. ${ }^{10}$

Two of the first such clinics were established in Seattle and Sydney: the Seattle Indian Health Board in 1970 and the AMS just six months later, in 1971. In both cases urban Indigenous people faced a common issue of structural invisibility that prevented them from accessing mainstream health services. Two factors worked symbiotically to exclude urban Indigenous people in Seattle and Sydney from accessing medical care in all but emergency cases before 1970. On the one hand, free government healthcare afforded to Indigenous people as part of historic agreements applied only to Indigenous residents of reserves or reservations; a person thus effectively 'lost' their Indigenous rights to healthcare as soon as they moved off the reserve or reservation. On the other hand, mainstream doctors in cities often refused to treat Indigenous patients, either assuming they were entitled to free government services or on the basis of blatant racism and indifference. So common was this experience, a well-known joke referenced it in the American Indian community in Seattle during the 1960s. It concerned an urban Indian seeking a room at a hospital: 'Did you hear the one about the Indian who couldn't get a room? He didn't have a reservation'. ${ }^{11}$ In short, in the postwar period, Indigenous people who relocated from rural to urban settings in both the United States and Australia (often at the government's encouragement) were simultaneously forced into mainstream healthcare on the one hand while they were actively excluded from it on the other. By the 1950s and 1960s, Indigenous people in cities were thus growing increasingly wary of mainstream health services because they were proving to be fruitless and inhospitable - often outright discriminatory - environments.

A comparison of this shared struggle across two different national contexts reveals a much larger political challenge faced by pan-Indigenous urban communities at this time: they were unable to gain federal government support and recognition as Indigenous peoples. As a result of moving into cities (and thereby 'assimilating'), it was argued they had forfeited any

9 Panaretto et al., 'Aboriginal', 650.

10 For example, 41 urban Indian health clinics now exist across the United States. In Australia, Indigenous community-controlled health services now serve both rural and urban populations, and thus a significantly higher number exist than in the US. There are 141 clinics currently operational in Australia.

11 Indian Center News, American Indian Women's Service League (AIWSL), 3, no. 1, February 1963. 
rights to special treatment as Indigenous peoples. Put simply, when urban Indigenous communities in these cities tried to make their grievances and health struggles heard in the late 1960s, they were told by municipal and federal authorities alike that they could and should access mainstream health services like all other citizens, or else they should access resources set aside for other 'minorities'. Not satisfied with being told they had essentially 'lost' their Indigenous rights and identities simply by virtue of relocating into cities, and not content to let the health issues of their communities worsen, activists in Seattle and Sydney alike were compelled by the early 1970 s to take measures into their own hands. Pan-Aboriginal and pan-Indian activists therefore created their own free grassroots medical clinics run by, and exclusively for, their own people.

The stories of how these clinics got off the ground and eventually won government support are fascinating and inspiring, but too lengthy to be reproduced here. Instead, I turn to what these clinics stood for, what they hoped to create and/or change, and how we might be able to read them as evidence of a political vision that enlarges the traditional scholarly focus on the history of Indigenous self-determination as a land-centric political project.

\section{Beyond land}

In 1967, Seattle resident and Indigenous activist Pearl Warren (Makah) told a reporter from the Seattle Post-Intelligencer that, in striving to create a place where urban Indians could receive free social services from their own people, the city's Indian community did not desire 'a reservation right in the middle of town'. All they wanted was a place 'where in our most vulnerable times of feeling unwell, we could feel free and proud to be ourselves'. ${ }^{12}$ Warren expressed a special regard for the importance of Indigenous people's freedom simply to be Indigenous at all times and places, but most especially when they were not in good health. Rather than seek jurisdictional control over territory, Warren asserted they were pushing back an assimilationist agenda that encroached into even the most vulnerable and private moments in an Indigenous person's life. The creation of their own social services was seen to be essential in achieving this political goal. Soon after the opening of their Indian

12 Pearl Warren in Bryant, 'Loneliness Is the White Man's City', 51. 
(Cultural) Center, in 1965 Warren again underscored the significance of their own community services in a lengthy message to members of the Seattle Indian community: 'For too long we have depended upon the non-Indians to do for us, the time has come when we must start doing more for ourselves and each other'. ${ }^{13}$

Compare Warren's comments here with those made in Australia by celebrated Aboriginal activist Ruby Hammond (Ngarrindjeri). During the 1980s, Hammond wrote an op-ed for the Sydney Morning Herald reflecting on the close relationship between Aboriginal land rights and community-run health services. She lamented the difficulties encountered by Aboriginal activists and communities across Australia who were struggling to achieve land rights: 'We are adapting every day. We have to adapt because we are living in a changing society'. And yet, precisely because of these challenges, she underscored the vital necessity of the work being done by Aboriginal health activists in cities: 'But the only way we will survive is if we have community-based services'. ${ }^{14}$

Warren and Hammond both underscored a subtle but important difference between the politics of territorial sovereignty (or 'land rights' in Australian parlance) and the model of Indigenous sovereignty that I suggest urban Indigenous health activists were striving to create with their medical services. Hammond's and Warren's comments call our attention to the ways we might read the actions of Indigenous activists in both nations as attempts to make an important distinction within the political project of Indigenous sovereignty, even if they were not yet using the language of self-determination. In their respective efforts to articulate and create a means by which their communities could start living in accordance with their own political, cultural and social goals and needs, Warren and Hammond shared a commitment to the idea that Indigenous peoples in their respective communities had to be in charge of their own affairs - that is, be self-determining. Yet, the strategy each advocated for achieving this was not the acquisition of territory, but rather the creation of their own community-controlled services. In their focus on self-governance, self-control and self-reliance through their community services, Warren and Hammond both challenged the statist assumption

13 Warren, 'Pearl's Message', 2.

14 Hammond, 'Land Rights: Key to Aboriginal Health', Sydney Morning Herald, 1982. (Precise date unknown, but newspaper clipping can be found in Hannah Middleton Papers, ML MSS 5886, Box 7, New South Wales State Library, Sydney.) 
that legal monopoly over a territory must necessarily be the only or even most effective way by which a group collectively governs itself or, as we might say, achieves self-determination. In fact, the innovative character of their political ambitions is evident in how Warren and Hammond each proposed a new and different social mechanism that would allow Indigenous people who had no recourse to nationhood status or to land claims as a group (such as many people in cities), to nonetheless find ways to exist as a recognisable community, exercise self-governance and, eventually, make claims on the federal government for financial support. In Warren's words, this could be achieved, not by creating a reservation in the middle of town, but by creating another kind of space that would allow Native people to practise their culture freely and to feel a sense of community, especially during difficult times. In Hammond's words, this could be achieved explicitly by creating community-controlled organisations.

This move serves as an important reminder that many urban Indigenous people do have a claim to nationhood status in cities. For some, fighting for recognition of urban communities as authentic Indigenous communities with rights as such, thus can be about demanding urban territory as Indigenous territory. Second, it underscores that, in the case of the activism that created Indigenous health clinics, it is clear these claims were pressed on the basis of a pan-Indigenous identity rather than a national or tribal one. Third, Warren's and Hammond's comments might be read in ways that suggest the irrelevance of particular location to the status of these 'non-reservation' spaces as Indigenous, and thus they evinced the non-territorial basis of the underlying rights they were meant to uphold.

It is important to note in both examples that urban Indigenous health activists made a distinction between, on the one hand, what we might regard as the right of the community to be self-determining, and on the other hand, the right of the community to be able to be self-determining on a specific piece of territory under their control. For ease, we can refer to the former as recognising the right to 'self-governance' or 'selfdetermination', and to the latter as the right to 'territorial sovereignty' (although, both ideas still fall under the broad concept of sovereignty in the sense I have been using the term). As a practical matter, by seeking the right to be self-governing as opposed to the right to territorial sovereignty, urban Indigenous health activists made a substantive claim about the goals of Indigenous sovereignty as a whole. Their efforts supported the idea that securing territory, rather than being the only goal of Indigenous 
sovereignty, was just one aspect of it - to be sure, an undeniably important one. But, as their actions demonstrate, they believed a meaningful form of self-determination could be realised for peoples who did not seek territorial control or claims to nationhood.

In pressing for forms of de-territorialised control over their own affairs, urban Indigenous health activists did not seek to displace the importance of land claims (it was never an 'either/or' argument), they simply intended to make room for other political endeavours. Their goals were thus ultimately expansive; they sought to extend the reach of Indigenous self-determination such that it could be realised by Indigenous people in all contexts at all times, not only when they were within the bounds of recognised Indigenous territories.

Understanding how postwar urbanisation and the ensuing growth of an Indigenous diaspora in cities brought on these changes in the political goals of those Indigenous communities means reframing the history of Indigenous political activism in the 1960s and 1970s. Although at this time urban Indigenous communities led the way in political and social movements to protect sovereign homelands (Red Power, Alcatraz, Aboriginal Tent Embassy), these experiences only sharpened a collective realisation among urban communities that their pan-Indigenous political and cultural life in cities was neither represented nor protected by territorial sovereignty. They imagined a common terrain linking separate reservations/reserves with the growing urban Indigenous communities hailing from diverse origins. They imagined their community this way because it actually represented how many of them lived - with family members split across rural and urban locales, and with many urban migrants travelling back and forth. Indeed, a continuing connection with rural homelands was, for many urban people, an important reason to stand in solidarity with struggles for land rights and territorial sovereignty in the first place. That is, even though territorial sovereignty may not have benefited them directly in cities, urban pan-Indigenous activists fought for it since territorial sovereignty benefited their families, friends and communities. Indeed, they saw urban and reserve/reservation populations as part of the same community, and as sharing in the same political struggle. Bearing this out, in the 1960s, Aboriginal urban migrants in Australia came to speak of themselves and of all Aboriginal people as 'Black'. ${ }^{15}$

15 Jones and Hill-Burnett, 'Political Context of Ethnogenesis'; McGregor, 'Another Nation'; McGregor, Indifferent Inclusion. 
Similarly, as urban Indian communities grew in US cities in the late 1950s, community members initially made contact with other Indians in the city via pre-existing networks from reservations, tribal nations and boarding schools. Gradually, these contacts combined with the exigencies of urban life to create a pan-Indian or what sociologist Stephen Cornell calls a 'supra-Indian' identity: a 'pan-ethnic' identity based on shared histories of responding to racist federal Indian policies and on a syncretic culture of tribally specific, intertribal and newly invented traditions. ${ }^{16}$ Much like the language of 'Black Power' in Australia, the language of 'Red Power' in the United States drew little distinction between how this politics and a generalised 'Indian' identity applied to urban versus rural communities. By speaking generally of Red Power, urban Indian activists also asserted their communities and rural Indian communities were linked; in fact, they were the very same community.

In both the Indigenous Red Power and Black Power movements, a vocal anti-colonialism with ties to the global decolonising struggles of the postwar era blended with a new awareness of local constructions of race ('Black' and 'Red'). Activists in Seattle and Sydney used their communityrun clinics to assert ideas about their identity and rights as Indigenous peoples that provided alternative plot lines to the fiction of assimilation that falsely dichotomised rural and urban Indigenous communities and erased the realities of continuing political, social, cultural, familial and economic ties between them. Remembering back to their strategising in the 1970s, Dr Walt Hollow (Assiniboine-Sioux), one of the Seattle Indian Health Board's first physicians, recalled the emphasis the early founders of the clinic placed on their treaty rights, even as urban Indians living offreservation: 'The treaty said we were to get healthcare. And here we could demonstrate that there were a group of Indians living in Seattle, who were not getting regular healthcare. ${ }^{17}$ Drawing little distinction between the political struggles of urban and rural communities, urban Aboriginal activists often spoke up on behalf of rural communities, referring to people within those communities as 'our brothers and sisters. ${ }^{18}$ And, in defending territorial sovereignty even when it did not directly stand to benefit their pan-Indigenous communities in cities, activists in the postwar period pursued a pan-Indian and pan-Aboriginal politics that connected cities and reservations, as a counter-narrative to the romances of assimilationist

16 Cornell, The Return, 33.

17 Walt Hollow, interviewed by the author, Seattle, WA, 18 August 2013.

18 Black News Service 3, no. 3 (1977). 
'melting pots' imagined by Australian and American national history and federal policy. Ruby Hammond, for example, in her work advocating for the importance of Aboriginal health as a political priority, often spoke of how 'land rights is fundamental to any improvements in the health of Aboriginal people. ${ }^{19}$

Ironically, the visibility of the territorial struggles urban activists fought for on behalf of rural communities in the 1960s and 1970s often obscured efforts to protect their own (non-territorial) sovereignty in cities. The shift towards imagining Indigenous self-determination in forms that could exist apart from territorial politics also took place slowly, which made it harder to observe. However, the community-controlled health clinics (and the political struggles that built them) were key contexts in which this vision took shape, and hence I suggest that these clinics ultimately became an expression and embodiment of this de-territorialised politics. Even when the clinics later pushed for federal funds as a means of more explicitly advancing their claim that their communities had a right to government support, they insisted they would only take government funds free of restrictions. This was a reiteration of their concern for autonomy from government control but was simultaneously a means to assert the government's obligation to support their communities given the special obligations owed to Indigenous peoples by the US and Australian federal governments.

With the clinics themselves embodying the ideal of a 'de-territorialised' form of sovereignty, they might also be considered as mobile mini sovereign zones or 'hubs', where Indigenous people were in control of their own affairs and free to gather and associate as a community on terms they set. In using this language of the 'hub', I draw from the work of anthropologist Renya K. Ramirez, who writes:

The hub suggests how landless Native Americans maintain a sense of connection to their tribal homelands and urban spaces through participation in cultural circuits and maintenance of social networks, as well as shared activity with other Native Americans in the city and on the reservation. ${ }^{20}$

19 Hammond, 'Land Rights: Key to Aboriginal Health'.

20 Ramirez, Native, xx. 
As a cultural, social and political concept, for Ramirez the hub ultimately has the potential to 'strengthen Native identity and provide a sense of belonging, as well as to increase the political power of Native peoples'. She also describes 'hub-making activities' as practices that 'bridge tribal differences so Native Americans can unify to struggle for social change'. ${ }^{21}$ I borrow this language of the hub, with its emphasis on urban and rural mobility, diasporic Indigenous identity and connection, as well as political and social innovation, to conceptualise the social, cultural and political significance of urban Indigenous health clinics as a kind of 'native hub'. On this reading, referring to the clinics as 'health hubs' (indexing a shift away from specific land/territories), and which in theory could be located anywhere, registers how they freed the project of Indigenous sovereignty considerably and provided Indigenous peoples a capacious means to exercise their self-determination wherever they lived.

If this constitutes one way in which urban health activists de-territorialised the project of Indigenous sovereignty through their clinics, their health activism also served to drastically reconfigure the political goals of Indigenous sovereignty by directing the concern for self-determination to the level of individual bodies. (Here, arguably, we can trace the most direct line of connection to ways in which the language of sovereignty now functions with increasing frequency in twenty-first-century Indigenous political discourse.) In a certain sense, of course, this concern that individual Indians/Aboriginals exhibit agency and control over their bodies and medical affairs looks similar to the liberal concern that individuals have sovereign control over their own bodies. I contend, however, that the health activists' concern with the bodily sovereignty of their respective community members was distinctive in a number of important respects.

First, in the case of Indigenous peoples, health activists did think Indigenous bodily sovereignty required a particular social, political and cultural context in order to be fully realised. Namely, it was believed what was needed, instrumentally speaking, to ensure the self-determination of Indigenous individuals, was precisely the kind of social and political environment provided by services run by and for Indigenous people. In other words, the dignity and autonomy of Indians and Aboriginals in their medical affairs, and their concomitant capacity to exercise bodily

21 Ramirez, Native, 3-8. 
integrity, required a set of institutions that catered to their Indigenous identity. Thus activists were concerned to ensure their community members could enjoy individual dignity and bodily control in their medical affairs as Indians and as Aboriginals. This is perhaps what Pearl Warren meant, when she said all the Seattle Indian community wanted was a place 'where in our most vulnerable times of feeling unwell, we could feel free and proud to be ourselves'.

Second, while many activists no doubt shared the 'liberal' aspiration that individual Indigenous persons enjoy autonomy over their own bodies and medical care qua individual subjects, I contend the activists' concern with the bodily integrity and sovereignty of their communities' members manifested a distinct set of Indigenous normative concerns. Structures of colonial governance decimated and undermined Indigenous communities in the United States and Australia, and, importantly, this was often manifested most acutely at the level of individual Indigenous bodies. In this context, ensuring the health and integrity of individual Indigenous persons became a form of resistance to continuing colonisation in the twentieth century (assimilation) that worked to undermine the integrity of Indigenous communities. In other words, the health of the Indigenous community and its own capacity for self-direction was predicated on ensuring the health and bodily sovereignty of its individual members, just as the concern for the self-determination of individuals within that group was also advanced by the health of the group as a whole. Hammond expressed precisely this when she extolled the work of the AMS in 1980, writing:

The Redfern Service, however, offers an impressive example of the advantages of such community run organisations - their total commitment to the task [of self-determination], their acceptance by the target population and their vital role in the total development of the Aboriginal community by supporting individual people and the larger community. ${ }^{22}$

Providing for the health of individual members in the way specified through Indigenous-run organisations - was thus thought to be necessary to the self-determination of the community. Seeing the clinics in this light points to the important role health issues played as part of the wider narrative sweep of Indigenous activism in Australian and United 
States history. Many scholars have recently recognised that, as Indigenous people in both the United States and Australia moved off reserve or rural land in the second half of the twentieth century and started living in ways that complicated and defied a simple binary between urban and rural communities, the meanings of Indigenous sovereignty were reconfigured in response to these demographic and geographic changes. Typically, the imprint of these social and political shifts has been recognised in advocacy for self-determination that came to be associated with land rights or territorial claims and associated efforts to prove ongoing attachment to specific lands and waterways in the late 1960s and 1970s. Scholars have already noted how, as Indigenous communities became more diasporic in the postwar period, the need arose to protect ongoing attachments to specific territories. By contrast, I argue the concurrent efforts to protect Indigenous health in cities put forward a new and different set of ideas about Indigenous self-determination both in response to and to expand upon the limited reach of a territorial model of Indigenous sovereignty. Rather than developing in separate and isolated ways, ideas about Indigenous sovereignty were multifaceted, responsive and contested in the postwar world. In particular, Indigenous migration and mobility in Australia and the United States in the 1950s and 1960s raised all sorts of questions - for the newly transplanted in particular - about the status of any rights and recognitions enjoyed by Indigenous peoples in their new settings. Did Indigenous rights travel along with the people? Was Indigenous identity lost outside of the reserve and traditional territories?

I argue here and elsewhere that urban Indigenous communities' fight for healthcare as Indigenous peoples in the 1960s and 1970s elevated the significance of self-governance and articulated a politics of the body that offered alternative foundations for Indigenous sovereignty to what they perceived as a limiting and limited focus on land and jurisdiction, both of which, the federal governments of Australia and the United States sought to enforce. In their struggle to assert urban Indigenous rights to healthcare, and to be recognised in the cities as communities that were culturally continuous with reserve and reservation communities, panIndigenous urban activists in Seattle and Sydney grappled head-on with the reality that the project of colonisation and assimilation was never only about land. In postwar cities, where Indigenous people lost even the modicum of territorial sovereignty they had on reserves and reservations, resisting colonisation and defending Indigenous sovereignty turned on defying assimilation and asserting the continuities of their cultural and 
political identities regardless of where they resided. They aimed to show that Indigenous communities remained cohesive even if they lived in ways that cut across geographic borders and even if their cultures changed (became 'pan-Indigenous') in new settings. These health activists made the argument that, by moving off recognised Indigenous lands, urban migrants were not forfeiting their Indigenous rights but, rather, were expanding the boundaries of Indigenous life and thus of Indigenous rights. Urban Indigenous health activists recognised the extension of assimilationist and colonial pressures into even their most private spaces (seeing a doctor), and thus pressed a case for reconceptualising the 'terrain' through which, and on which, Indigenous sovereignty could be asserted. They de-emphasised territory and elevated the significance of their own organisations and their own bodies in the struggle for Indigenous selfdetermination. In setting their sights beyond land in these specific ways, it is unsurprising health struggles became a key site for the political reconfiguration of Indigenous sovereignty and self-determination in the twentieth, and into the twenty-first centuries.

\section{References}

Alfred, T. 'Sovereignty'. In Sovereignty Matters: Locations of Contestation and Possibility in Indigenous Struggles for Self-determination, edited by J. Barker, 33-50. Lincoln: University of Nebraska Press, 2005. doi.org/10.2307/j.ctt1d nncqc. 5 .

Barker, J. 'For Whom Sovereignty Matters'. In Sovereignty Matters: Locations of Contestation and Possibility in Indigenous Struggles for Self-determination, edited by J. Barker, 1-32. Lincoln: University of Nebraska, 2005. doi.org/ 10.2307/j.ctt1dnncqc. 4 .

Bryant, H. 'Loneliness Is the White Man's City'. In The Red Man in America, 50-52. Olympia: Office of the State Superintendent of Public Instruction, 1970 .

Cornell, S. The Return of the Native: American Indian Political Resurgence. New York: Oxford University Press, 1988.

Deloria, V., Jr. 'Intellectual Self-determination and Sovereignty: Looking at the Windmills in Our Minds'. Wicazo Sa Review 13, no. 1 (1998): 25-31. doi.org/ 10.2307/1409027. 
Engle, K. 'On Fragile Architecture: The UN Declaration on the Rights of Indigenous Peoples in the Context of Human Rights'. European Journal of International Law 22, no. 1 (2011): 141-63. doi.org/10.1093/ejil/chr019.

Hammond, R. 'Land Rights and Aboriginal Health' Lecture. Hannah Middleton Papers, ML MSS 5866. Mitchell Library, Sydney.

Hannah Middleton Papers, ML MSS 5866, State Library of New South Wales, Sydney.

Jones, D. J. and J. Hill-Burnett. 'The Political Context of Ethnogenesis: An Australian Example'. In Aboriginal Power in Australian Society, edited by Michael C. Howard, 214-46. St Lucia, Qld: University of Queensland Press, 1982.

McGregor, Russell. 'Another Nation: Aboriginal Activism in the Late 1960s and Early 1970s'. Australian Historical Studies 40, no. 3 (2009): 343-60. doi.org/ 10.1080/10314610903105217.

McGregor, Russell. Indifferent Inclusion: Aboriginal People and the Australian Nation. Canberra: Aboriginal Studies Press, 2011. doi.org/10.1017/jie.2013.1.

Panaretto, K., M. Wenitong, S. Button and I. Ring. 'Aboriginal Community Controlled Health Services: Leading the Way in Primary Care'. Medical Journal of Australia 200, no. 11 (2014): 649-52. doi.org/10.5694/mja13.00005.

Raheja, M. 'Reading Nanook's Smile: Visual Sovereignty, Indigenous Revisions of Ethnography, and "Atanarjuat (The Fast Runner)"'. American Quarterly 59, no. 4 (2007): 1159-85. doi.org/10.1353/aq.2007.0083.

Ramirez, R. K. Native Hubs: Culture, Community, and Belonging in Silicon Valley and Beyond. Durham: Duke University Press, 2007. doi.org/10.1215/ 9780822389897.

United Nations. United Nations Declaration on the Rights of Indigenous Peoples. Resolution adopted by the General Assembly, 13 September 2007. March 2008. Accessed 28 November 2019. www.un.org/esa/socdev/unpfii/documents/ DRIPS_en.pdf. doi.org/10.1163/2211-4394_rwilwo_sim_032185.

Warren, Pearl. 'Pearl's Message'. Indian Center News 4, no. 25 (19 February 1965): $1-2$. 
This text is taken from Indigenous Self-Determination in Australia: Histories and Historiography, edited by Laura Rademaker and Tim Rowse, published 2020 by ANU Press, The Australian National University, Canberra, Australia.

doi.org/10.22459/ISA.2020.09 